\title{
AN EQUATION FOR ESTIMATING THE (R) USLE SLOPE STEEPNESS FACTORS
}

\author{
Dr. Matthew K. Mulengera \\ Department of Agricultural Engineering and Land Planning, \\ Sokoine University of Agriculture, P. O. 3003, Chuo Kikuu, Morogoro, Tanzania \\ email: mulengera@yahoo.com
}

\begin{abstract}
Currently three equations are used for calculating slope steepness factor for the Revised Universal Soil Loss Equation (RUSLE); one for slopes less than nine percent, the second for slopes equal or greater than nine percent, and the third equation that has been proposed for use in China for slopes equal or greater than 17 $\%$. The three equations have linear relationships between slope steepness factor, $S$ and the sine of the slope angle, $\theta$. The three equations under predict the factor, $S$ when used on slope steepness beyond the data sets used to develop them. In addressing this problem several alternative forms of equations (linear, power, and polynomial) were tested using field plot soil loss data gathered by several researchers in different countries for slopes ranging from three percent to $55 \%$. A single power function relating the sine of the slope angle, $\theta$ to the slope steepness factor, $S$ has been identified to be more suitable and accurate for estimating the RUSLE slope steepness factor, $S$.
\end{abstract}

Keywords: Slope steepness factor; Soil loss prediction; Statistical regression

\section{Introduction}

The slope steepness factor, $\mathrm{S}$ for the (Revised) Universal Soil Loss Equation is the ratio of soil loss from a field with given slope gradient to that from a field with slope gradient of nine percent under otherwise identical conditions (slope length, soils, soil moisture regimes, rainfall, and management) (Wischmeier and Smith, 1978). The slope steepness (gradient) affects soil erosion because it affects soil detachment and transport by rainfall splash (Brian, 1979; Savat, 1981) and runoff (Wischmeir and Smith, 1978). The relationship of slope steepness to soil loss is influenced by its interactions with soil properties, vegetation types, surface roughness, and residue management (Wischmeier and Smith, 1978; Liu et al,1994), and rainfall characteristics (Liu et al, 1994).

Different researchers have found varying relationships between slope steepness and soil loss. Zingg (1940), using simulated rainfall on slopes up to $20 \%$, and Musgrave (1947), using composite data from slopes up to $16 \%$ found the slope steepness factor, $\mathrm{S}$ equation of the form:

$$
S=\left(\frac{s}{9}\right)^{n}
$$

Where, $\mathrm{s}$ is the tangent of the slope angle and $\mathrm{n}$ is 1.4 or 1.35 respectively.

Smith and Wischmeier, (1957) using data from runoff plot with gradients varying from three percent to $18 \%$ developed the slope steepness factor equation of the form:

$$
S=0.0065 s^{2}+0.0453 s+0.065
$$

Wischmeier and Smith (1978), realising that shear stress of the surface flow is related to the sine of the slope angle (Chow, 1959), used same data for equation 2 to develop the slope steepness factor of the form:

$$
S=65.4 \sin ^{2} \theta+0.0453 \sin \theta+0.0654
$$

McCool et al., (1987) using data from simulated rainfall for slopes of $0.1 \%$ to three percent and data from natural rainfall for slopes of three percent to $18 \%$ and Liu et al. (1994) using data from natural rainfall for slopes of nine percent to $55 \%$, developed equations of the form: 


$$
S=A \sin \theta+B
$$

Where, A equals to $10.8,16.8$, or 21.91 and $\mathrm{B}$ equals to $0.03,-0.5$, and -0.96 respectively.

Although for the slope steepness ranges used the linear relationship between soil loss to the sine of the slope angle was statistically more accurate the increasing gradients of the equations with increasing slope steepness suggest that using the equations for land slopes beyond that used to develop them results in under prediction of soil loss. This poses problems in planning soil conservation in mountainous regions where cultivation of steeper slopes is common. In this study an equation which can be used for all land slopes, giving accurate predictions is presented.

\section{Materials and Methods}

Data on slope steepness and soil loss for slopes ranging from three percent to $55 \%$ were assembled from different literature sources (Wendelaar, 1978; Liu et al., 1994; Vogel, 1994; Mulengera; 1996). All the data came from natural runoff plot research. All soil loss data not normalized to nine percent slope as required for use in the RUSLE were normalized (Murphree and Mutchler, 1981).

The Microsoft Excel software was used for statistical regression analysis. Tangent values of slope angles and sine values of the slope angles were used to test the three different functional forms, (i.e. linear, polynomial, and power) to identify the most consistently accurate equation(s) for estimating the slope steepness factor, $\mathrm{S}$.

\section{Results and Discussion}

Figures one to three and table 1 show some of the statistical regression analysis results for the slope steepness and soil loss relationships. The three expressions shown are the best results from the regression analysis. Table one shows that the equations are almost equally accurate. All are statistically significant at more than $99.95 \%$. The slope steepness factor equation of the polynomial form (Fig. 2) predicts zero soil loss when gradient equals $1.3 \%$ and below this value the equation predicts negative soil loss (deposition). Equation 3 by Wischmeier and Smith (1978) developed using data for slopes ranging from $3 \%$ to $18 \%$ does not predict zero soil loss even when the slope is zero. Because its development used more data from low slopes it should be considered more accurate within its data range. Thus, the polynomial equation developed in this study is not as good as that by Wischmeier and Smith (1978) for land slopes below the lowest value of runoff plots data used for its development (i.e. three percent). 


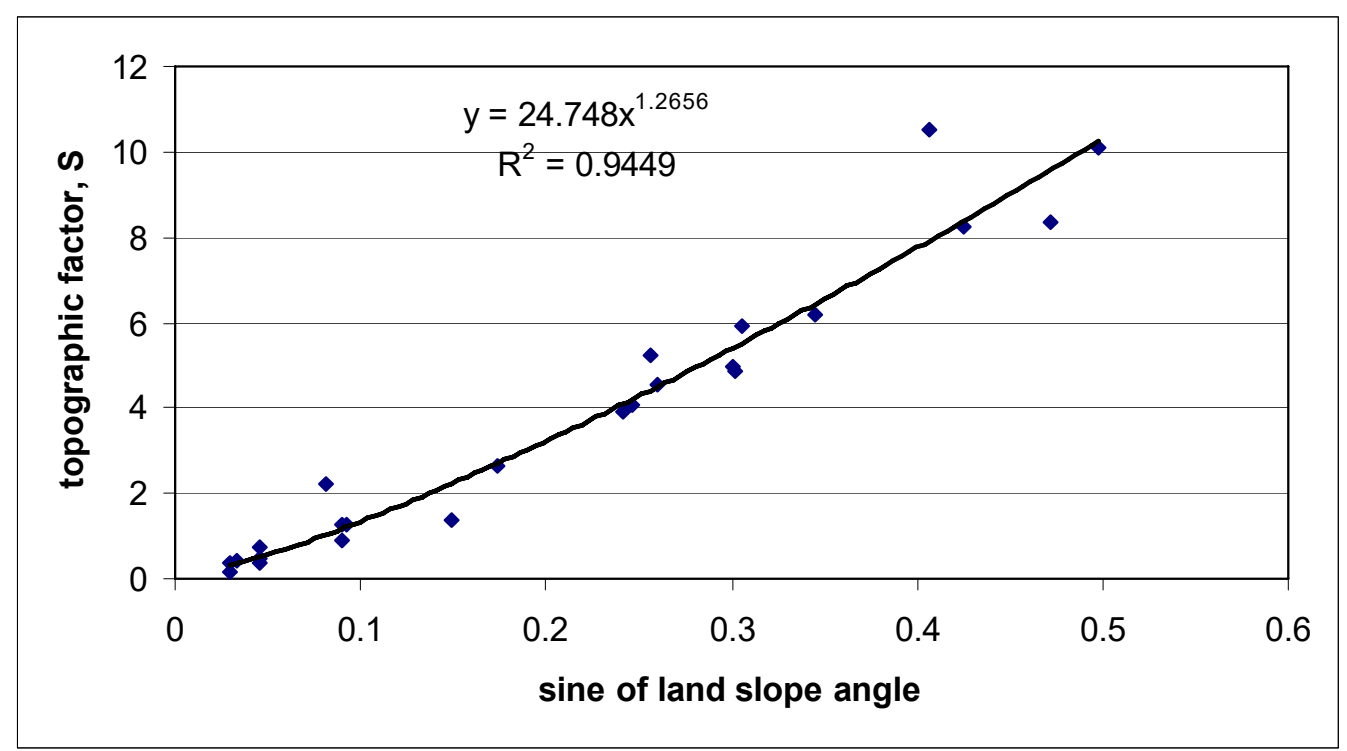

Fig. 1: Power function relating topographic factor, $S$ to sine of slope angle, $\theta$

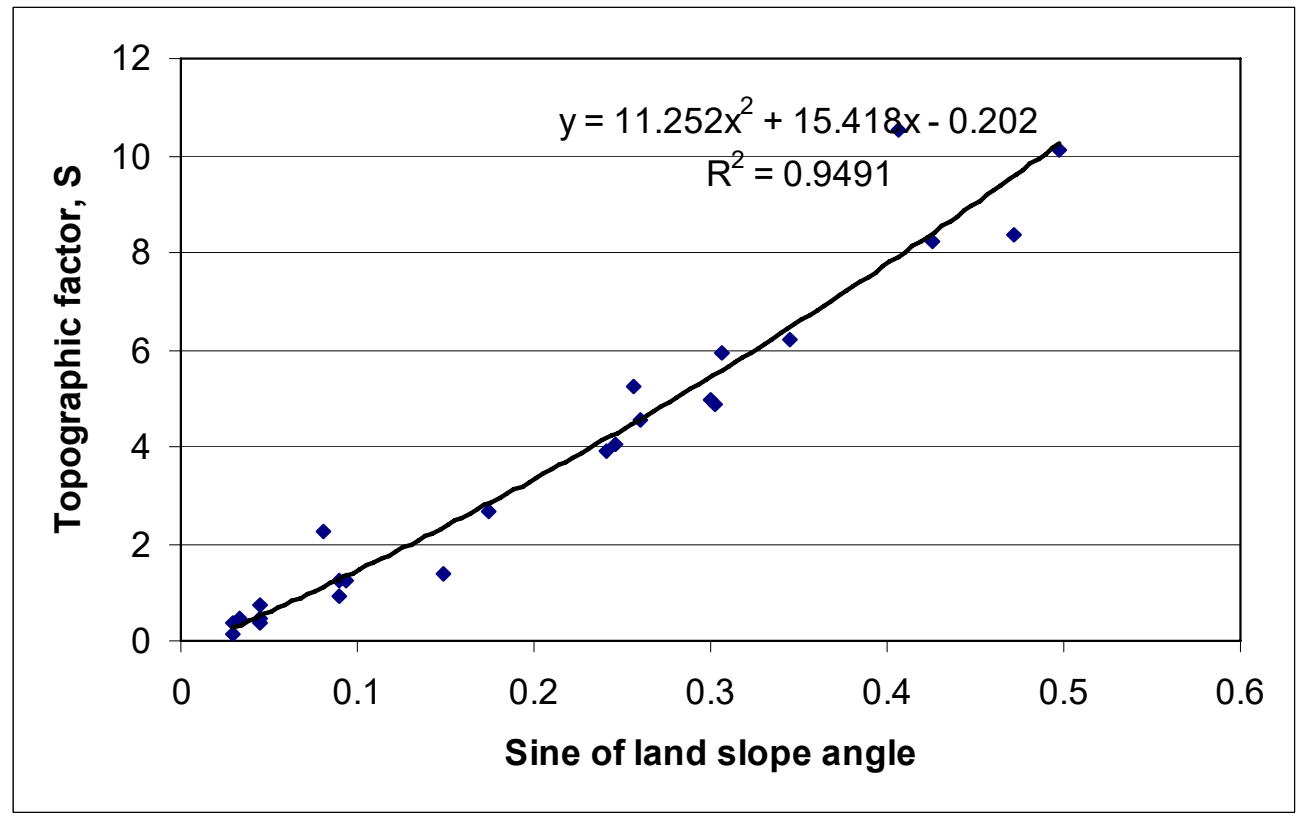

Fig.2: Polynomial function relating topographic factor, $S$ to sine of slope angle. $\theta$ 


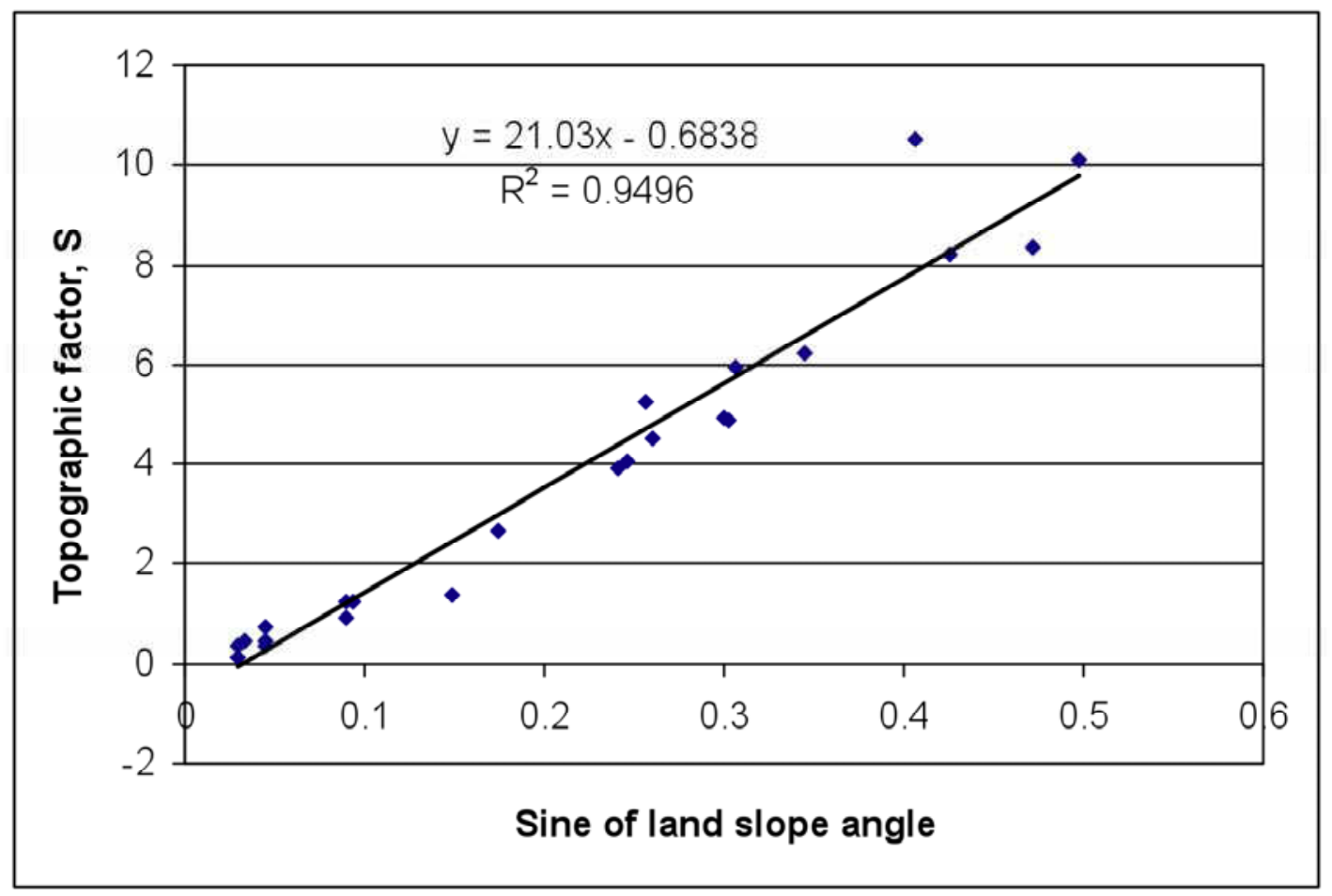

Fig. 3: Linear function relating topographic factor, $S$ to sine of slope angle, $\theta$

Table 1: Some statistical analysis output for the regression equations

\begin{tabular}{|l|l|l|l|}
\hline Equation & $\begin{array}{l}\text { Coefficient of } \\
\text { determination, } \mathrm{R}^{2}\end{array}$ & $\begin{array}{l}\text { Residual standard } \\
\text { deviation, } \mathrm{S}\end{array}$ & $\mathrm{p}$-value \\
\hline$S=24.748(\sin \theta)^{1.2656}$ & 0.945 & 0.76 & $<<0.0005$ \\
\hline$S=11.254 \sin ^{2} \theta+15.41 \sin \theta-0.202$ & 0.950 & 0.73 & $<<0.0005$ \\
\hline$S=21.03 \sin \theta+0.684$ & 0.950 & 0.73 & $<<0.0005$ \\
\hline
\end{tabular}

The regression line relating soil loss to slope gradient in this study (Fig. 3) is almost similar to that developed by Liu et al., (1994). This is due to the fact that out of the 24 data set used, only 7 data sets were those not collected by them and were below the slope range they used to develop their equation, (i.e. $9 \%$ ). Although the coefficient of determination for the linear function relationship is the highest (Fig. 3), the regression line passes below all the observed soil losses for slopes less or equal to $4.5 \%$. The equation predicts zero soil erosion when land slope is $3.25 \%$ and the equation predicts deposition for lower slope gradients. McCool et al., (1987) using more data for slopes ranging from $0.1 \%$ to $18 \%$ found that there was a break in regression line slope at $8 \%$ land slope. As a result they proposed the two currently used equations for calculating slope steepness factor of the RUSLE. The equation proposed by McCool et al., (1987) for slopes less than $9 \%$ does not predict deposition as is the equation 3 developed by Wischmeier and Smith (1978). Therefore, the linear equation developed in this study is also not as good as that by $\mathrm{McCool}$ et al., (1987) for use on low slope gradients.

The expression for slope steepness factor in Figure 1 predicts zero erosion when slope gradient is also zero and soil erosion prediction increases exponentially with slope. All the equations developed by researchers for low slopes predict soil erosion almost equal to zero when land gradient is zero (Wischmeier and Smith, 1978, McCool et al., 1987, Liu et al., 1994) and do no predict any deposition. 
Further comparison of the equation with the three currently used RUSLE slope steepness factor equations (McCool et al., 1987, Liu et al., 1994) for slope ranges proposed by Liu et al. (1994) shows that all the models predict almost same soil loss (Fig. 4). Only the equation by McCool et al., (1987) predicts less soil erosion for slopes greater than about $17 \%$ as was found by Liu et al., (1994).

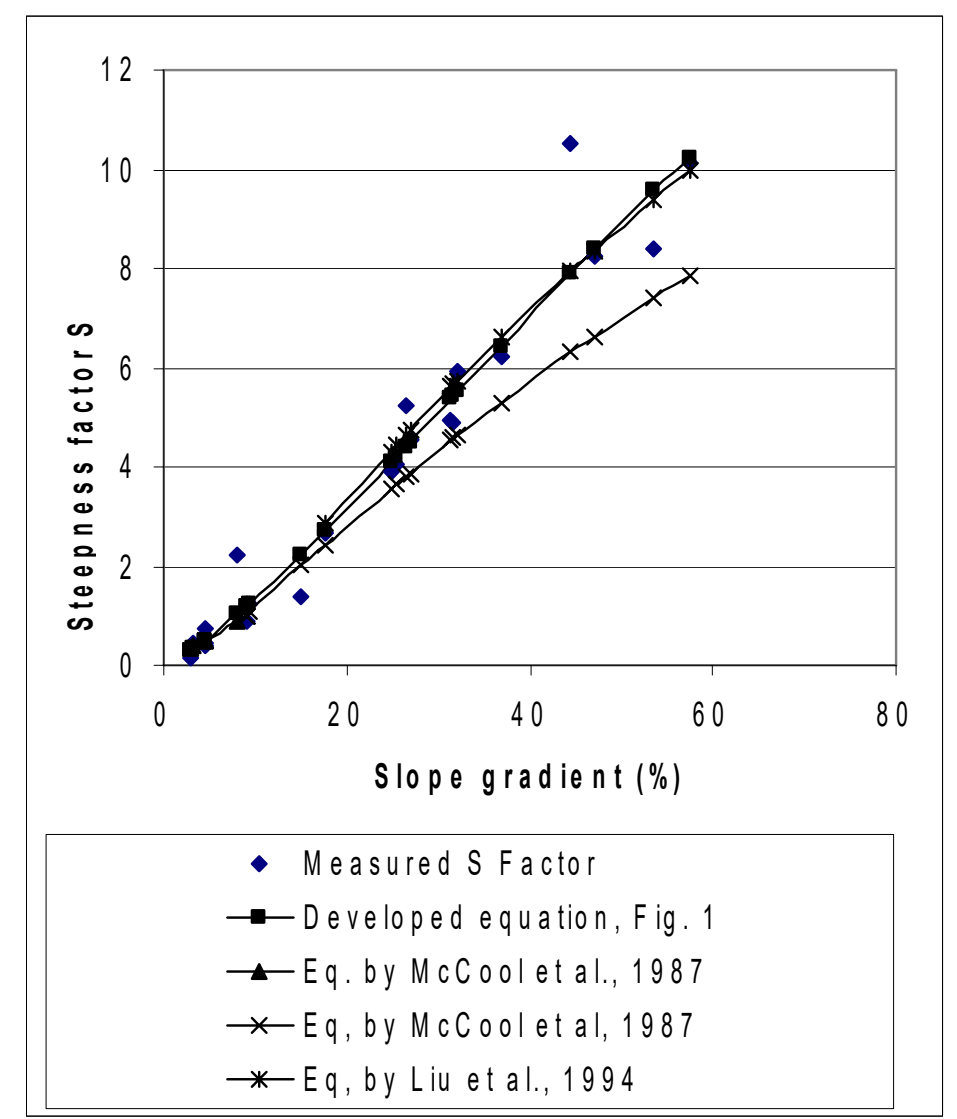

Fig. 4: Measured and predicted slope steepness factor values

\section{Summary and Conclusions}

Several equations have been proposed for calculating slope steepness factor of the revised USLE. Currently three equations are used, one for slopes less than nine percent, the second for slopes equal or greater than nine percent, and the third equation that has been proposed for use in China for slopes equal or greater than 17 $\%$. The three equations have linear relationships between slope steepness factor, $\mathrm{S}$ and the sine of the slope angle, $\theta$. The three equations under predict the factor, $\mathrm{S}$ when used on slope steepness beyond the data sets used to develop them.

Several alternative forms of equations (linear, power, and polynomial) were tested using field plot soil loss data gathered by several researchers in different countries for slopes ranging from three percent to $55 \%$. A single power function relating the sine of the slope angle, $\theta$ to the slope steepness factor, $\mathrm{S}$ has been identified to be more suitable and accurate for estimating the RUSLE slope steepness factor, $\mathrm{S}$ for all the slope ranges. As it has shown to be consistently accurate for all the slope steepness range of zero to $55 \%$, it is intuitively judged to be more accurate beyond the slope gradient range used to develop it.

\section{References}

Brian, R. B., (1979). The influence of slope angle on soil entrainment by sheetwash 
and rainsplash. Earth Surface Processes $4: 43-58$.

Chow, V. T., (1959). Open Channel Hydraulics. McGraw Hill ,New York.

Liu, B. Y., Nearing, M. A., and Risse, L. M., (1994). Slope gradient effects on soil loss for steep slopes. Trans. of the ASAE. Vol. 37(6):1835 - 1840.

McCool, D. K., Brown, L. C., Foster, G. R., Mutchler, C. K., and Meyer, L. D., (1987). Revised steepness factor for the Universal Soil Loss Equation. Trans. Of the ASAE 30(5): $1387-1396$.

Mulengera, M. K., (1996). Soil loss prediction in the semi-arid tropical savanna zone: A tool for soil conservation planning in Tanzania, PhD Thesis, Univ. of Newcastle upon Tyne, U. K., 232 p.

Murphree, C. E., and Mutchler, C. K., (1981). Verification of the slope factor in the Universal Soil Loss Equation for low slopes. J. of Soil and Water Conserv. Vol. 36(5): $300-302$.

Musgrave, G. G., (1947). The quantitative evaluation of factors in water erosion Afirst approximation. J. Soil and Water Conserv., 2(3): 133 - 138, 170.
Savat, J., (1981). Workdone by splash: Laboratory Experiments. Earth Surface Processes, 6: $275-283$.

Smith, D. D., and Wischmeier, W. H., (1957). Factors affecting sheet and rill erosion. Trans. Am. Geophys. Union, 36 (6): 889 $-896$.

Vogel H., (1994). Conservation tillage in Zimbabwe: Evaluation of several techniques for development of sustainable crop production systems in small holder farming, $P h D$ thesis, Univ. of Berne, Switzerland.Geographica, Bernensia, African Studies Series, No. A11, 150 p.

Wendelaar, F. E., (1978). Applying the Universal Soil Loss Equation in Rhodesia, Unrefenced Report, Inst. Agric. Eng., Harare, Zimbabwe.

Wischmeier, W. H., and Smith. D. D., (1978). Predicting rainfall erosion losses Aguide to conservation planning. U. S. Dept. of Agric., Agric. Handb., No. 537, $58 \mathrm{p}$.

Zingg, A. W., (1940). Degree and length of land slope as it affects soil loss in runoff. Agric. Eng. 21(2):59 - 64 